\title{
Ben W. Lichtenstein (1908-2003) and his contributions to our knowledge of spinal dysraphism
}

\author{
Sonja Salandy ${ }^{1} \cdot$ Santiago Gutierrez ${ }^{2} \cdot$ R. Shane Tubbs ${ }^{1,3}$
}

Received: 6 February 2019 / Accepted: 22 February 2019 / Published online: 2 March 2019

(C) Springer-Verlag GmbH Germany, part of Springer Nature 2019

\section{Introduction}

Ben W. Lichtenstein, MD (1908-2003) (Fig. 1 and cover), graduated from the University of Illinois College of Medicine in 1932, worked as a neuropathologist, and later became an associate professor of neurology in the Department of Neurological Surgery at the University of Illinois. He was interested in many neurological areas, but especially in spinal dysraphism composed of a wide range of neural tube defects with a broad spectrum of clinical manifestations.

\section{Lichtenstein's contributions to spinal dysraphism}

In his manuscript [2] published in 1940, Lichtenstein highlighted three cases of anomalies of the spinal cord. Intriguingly, Lichtenstein noted that spinal dysraphism might manifest in the absence of cutaneous or mesodermal defects, an idea that had not been studied before. However, it was the lack of clinical manifestations seen in some dysraphic states, especially involving the spinal cord, which piqued Lichtenstein's interest, as he noted that the paucity of such evidence might cause physicians to overlook a spinal cord disorder. He argued that terms such as spina bifida cystica and spina bifida occulta were restricting terms as they were unable to account for the associated cutaneous manifestations. Hence, he supported the use of terms such as "spinal dysraphism" or "the spinal dysraphic state" as more

\section{R. Shane Tubbs}

shanet@seattlesciencefoundation.org

1 Department of Anatomical Sciences, St. George's University, St. George's, Grenada

2 Pontificia Universidad Javeriana, Bogotá, Colombia

3 Seattle Science Foundation, 550 17th Ave, James Tower, Suite 600, Seattle, WA 98122, USA accurate denotations of the pleomorphic spina bifida group [2]. This concept was introduced before him by Bremer and Henneberg [1]. In this same manuscript, he described and classified the spectrum of defects classifying them as cutaneous, mesodermal, and neural and also hypothesized the mechanisms in which neural defects occurred describing the araphic and dysraphic states.

In 1942, Lichtenstein expanded his research on spinal dysraphism and reported cases illustrating the distant neuroanatomic complications of the dysraphic state. He noted that such disturbance was caused secondary to abnormal fixation of the spinal cord, its meninges, or its nerve roots, to impede the normal rostral migration of the spinal cord. Lichtenstein postulated that the degree and extent of such fixation paralleled the resulting severity of distant neuroanatomic complications experienced and proposed that tethering of the spinal cord could lead to paraplegia. Also, he found a correlation between the degrees of dysraphism and the development of hydrocephalus, noting the presence of hydrocephalus at birth in the ulcerative form of the condition and its failure to develop in less severe forms [3].

\section{Conclusions}

Lichtenstein agreed that hydrocephalus in most patients with spina bifida might lead to the formation of a Chiari malformation. However, he also believed that the Chiari malformation might be due to traction created by fixation of the spinal cord [3]. Hence, Lichtenstein's work in spinal dysraphism was essential to the development of our current understanding of spinal dysraphism, tethered cord syndrome, and their treatments. 
Fig. 1 and cover Collage of Lichtenstein (upper left and courtesy of University of Illinois College of Medicine [4]) and drawing from his 1942 paper (center and courtesy of American Medical Association, Published in the Archives of Neurology \& Psychiatry [3])
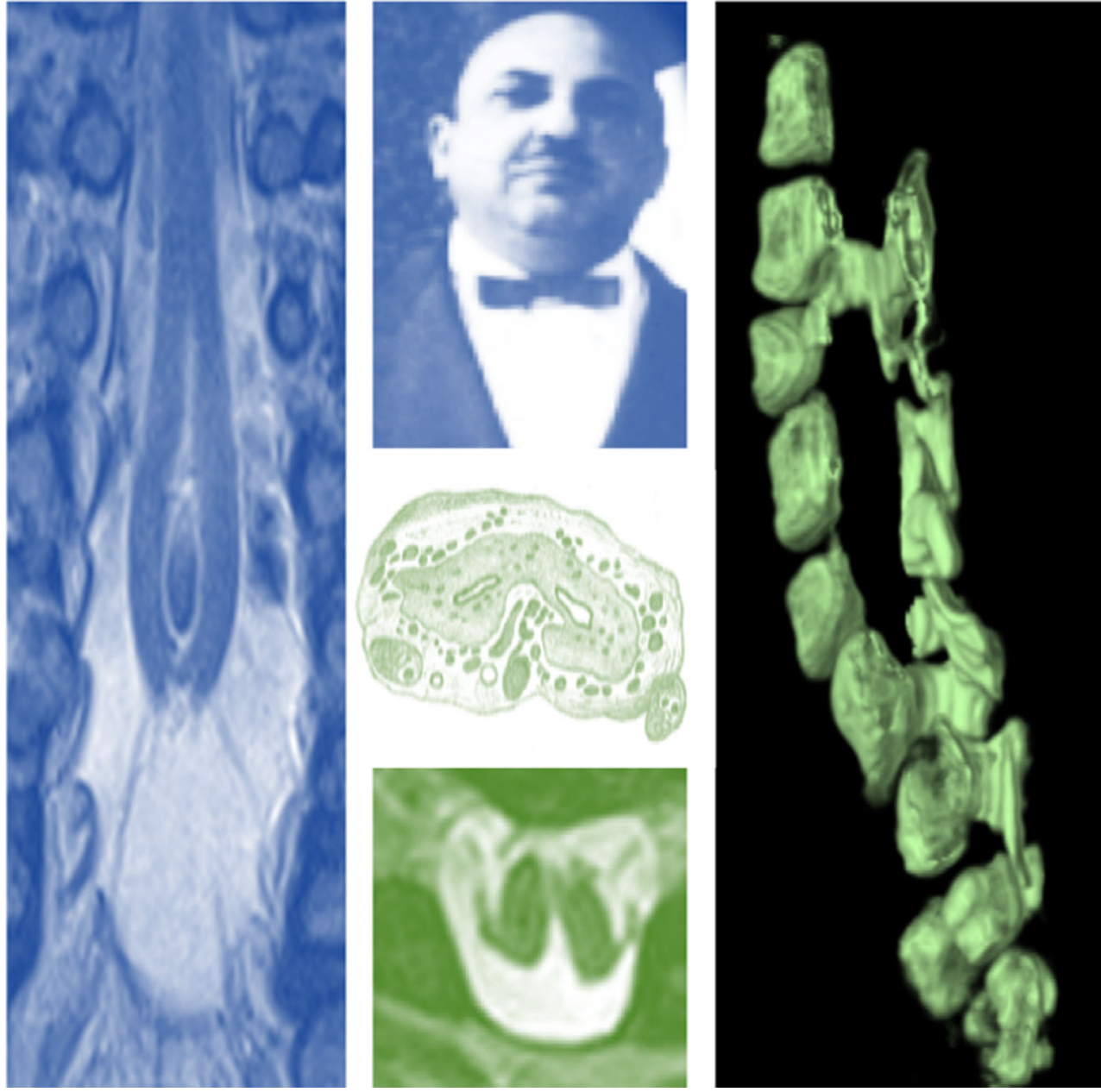

\section{Compliance with ethical standards}

Conflict of interest No conflict of interest.

Publisher's note Springer Nature remains neutral with regard to jurisdictional claims in published maps and institutional affiliations.

\section{References}

1. Bremer F (1926) Klinische Untersuchungen zur Aetiologie der Syringomyelie der Status dysraphicus. Dtsch Ztschr f Nervenh 95
2. Lichtenstein BW (1940) Spina bifida and myelodysplasia. Arch Neurol Psychiatr 44:792-810

3. Lichtenstein BW (1942) Distant neuroanatomic complications of spina bifida (spinal dysraphism): hydrocephalus, Arnold-Chiari deformity, stenosis of the aqueduct of Sylvius, etc.; pathogenesis and pathology. Arch Neurol Psychiatr 47:195-214

4. 086_LHSGEN-208-2, Photograph Subject File, University Archives, University of Illinois at Chicago Library 